\title{
Strengthening the link to adenosine
}

DOI:

10.1038/nrd2163
Although adenosine has been implicated in the pathophysiology of chronic lung disease, in vivo data supporting the role of specific adenosine receptor pathways are lacking. Sun and colleagues, writing in the Journal of Clinical Investigation, now provide evidence that the adenosine $A_{2 B}$ receptor $\left(A_{2 B} A R\right)$ is a major mediator in such conditions.

In vitro data indicate that activation of the $A_{2 B} A R$ by increased adenosine levels - which occur at sites of tissue injury and inflammation - might result in cellular effects relevant to the progression of lung disease. To test the hypothesis that $\mathrm{A}_{2 \mathrm{~B}} \mathrm{AR}$ contributes to the pro-inflammatory and tissue-destructive effects of adenosine in the lung, the authors used a mouse model of adenosine-

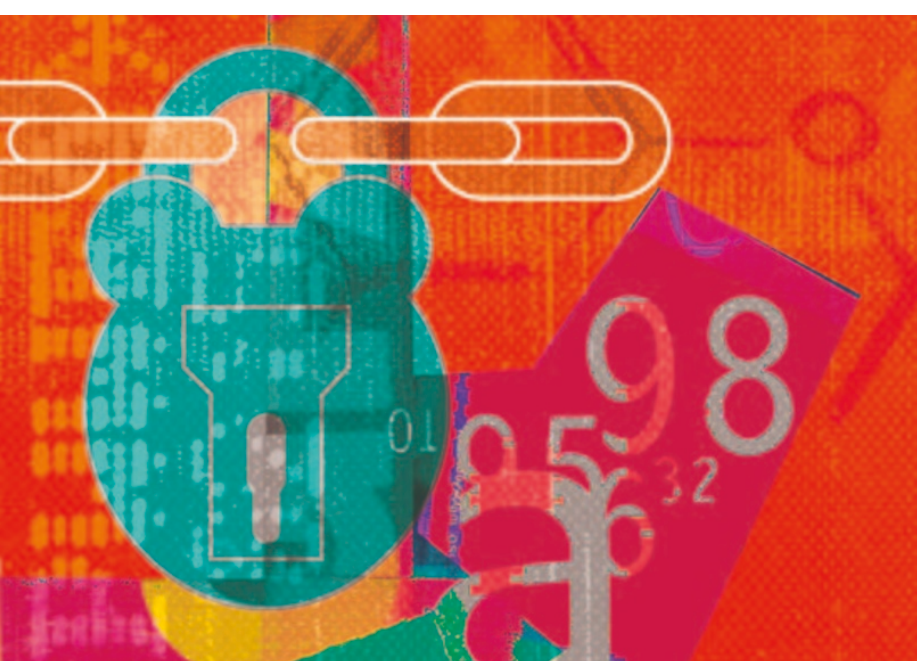

induced chronic lung injury. Mice deficient in the adenosine-metabolizing enzyme adenosine deaminase $\left(\mathrm{ADA}^{-/-}\right)$, which have increased levels of adenosine in lung tissues, show severe pulmonary inflammation, airway remodelling, fibrosis and enlargement of airspaces.

The authors utilized a novel antagonist, CVT-6883, which had high affinity, potency and selectivity for recombinant $\mathrm{A}_{2 \mathrm{~B}} \mathrm{ARs}$. Treatment of $\mathrm{ADA}^{-/-}$mice with CVT-6883 led to decreased lung inflammation, accompanied by a reduction in alveolar macrophages, lymphocytes, neutrophils and eosinophils. In addition, CVT6883 treatment led to lower levels of certain pro-inflammatory cytokines and chemokines, including tumournecrosis factor- $\alpha$, interleukin- 6 , chemokine (CC motif) ligands 11 and 17, and chemokine (CXC motif) ligands 1 and 2 .

An increase in mean-cord length of alveolar air space - a characteristic of emphysema in $\mathrm{ADA}^{-/-}$mice - was prevented by treatment with CVT-6883. Increased levels of adenosine-induced matrix metalloproteinases (MMP) and tissue inhibitors of metalloproteinases (TIMP), which act as regulators of alveolar integrity, are present in $\mathrm{ADA}^{-/-}$mice, and treatment with CVT-6883 also led to diminished expression of TIMP1, MMP9 and MMP12.

Next, the accumulation of pulmonary myofibroblasts was examined by staining for the fibrogenic marker smooth muscle $\alpha$-actin ( $\alpha$-SMA). Few $\alpha$-SMA-positive cells were seen in the alveolar airways of CVT-6883treated $\mathrm{ADA}^{-/-}$mice. CVT-6883 treatment also decreased the expression of the profibrotic mediators transforming growth factor- $\beta 1$ and osteopontin, and reversed the increased level of pulmonary $\mathrm{A}_{2 \mathrm{~B}} \mathrm{AR}$ transcripts seen in $\mathrm{ADA}^{-/}$mice. Finally, in an alternative, bleomycininduced pulmonary fibrosis model, CVT-6883 treatment resulted in decreased levels of pulmonary fibrosis and inflammation.

These data implicate the $\mathrm{A}_{2 \mathrm{~B}} \mathrm{AR}$ as a major mediator of chronic lung disease and suggest that antagonists of this receptor might have important utility in the treatment of conditions such as severe asthma, chronic obstructive pulmonary disease and pulmonary fibrosis. Further investigations to extend these observations to other lung diseases and humans are warranted; indeed, an initial Phase I study of CVT-6883 has been completed, in which the agent was well tolerated with no serious adverse events reported.

Charlotte Harrison

ORIGINAL RESEARCH PAPER Chun-Xiao, S. et al. Role of $A_{2 B}$ adenosine receptor signaling in adenosine-dependent pulmonary inflammation and injury. J. Clin. Invest. 116, 2173-2182 (2006) FURTHER READING Jacobson, K. A. \& Gao, Z.-

$\mathrm{G}$. Adenosine receptors as therapeutic targets. Nature Rev. Drug Discov. 5, 247-264 (2006) 